\title{
SIMPLE ESTIMATION OF AIR TEMPERATURE FROM MODIS LST IN GIFU CITY, JAPAN
}

\author{
Ali Rahmat \\ The United Graduate School of Agricultural Science, Gifu University, 1-1 Yanagido, Gifu 501-1193, \\ Japan
}

\begin{abstract}
:
In the developing country or poor country, the access to the meteorological data of air temperature is limited due to the lack of equipment or funding constraint. Air temperature is one of the meteorological data commonly used to predict evaporation in order to understand the climatic condition in a specific location. Nowadays, satellite data can be used to estimate some meteorological data. However, the detail explanations about how to get and how to use satellite data are limited and difficult to adopt especially for beginners. This paper explains how to acquired MODIS LST in order to estimate air temperature data in Gifu City, Japan. The data from MODIS LST is higher than the data directly measured from the local meteorological station for day time while the data extracted from MODIS LST is lower at night time compared with direct measurement. However, it still can be used because the pattern that was produced is similar. In addition, the Mean of maximum air temperature and minimum air temperature can be used as the average of air temperature in a daily basis. It is also certain that MOD11A2 product data is better than MYD11A2 data in estimating air temperature. Even though the MODIS LST has several limitations, the data still can be used to predict air temperature especially for remote areas like desert or forest where the ground measurement station has not been established.
\end{abstract}

Keywords: Air temperature, Climate, Gifu city, Meteorological data, MODIS.

\section{INTRODUCTION:}

Meteorological data is one of the most important components to support agricultural activities, disaster prevention, and an indication of environmental condition. Air temperature $(\mathrm{Ta})$ is a key variable used to describe environmental conditions [3]. Air temperature plays an important role in energy balance and it is a key input in various environmental models and applications, such as crop evapotranspiration estimation [2] or climate change models [4]. Traditionally, surface air temperatures are obtained from meteorological stations at 1.5-2 meters above the ground. In general, meteorological stations are distributed sparsely that is not enough for higher resolution regional model. Furthermore, in developing country meteorological stations is limited only in some area.

In recent decades, the advent of satellite technologies has seen rapid growth with a vital development of new methodologies to be utilized by different disciplines. Remotely sensed land surface temperatures (LST) can serve as an effective proxy for air temperature estimation in such areas. Superior to limited ground measurements, remote sensing can provide more spatiotemporal information. Several studies have estimated air temperatures using Moderate Resolution Imaging Spectroradiometer (MODIS) land surface temperature products in Portugal [1]. However the explanation how to obtain MODIS data is limited. This paper will provide the detail procedure about how to obtain the MODIS data and how to use satellite data for specific purposes.

\section{METHODS:}

The MODIS products of MYD11A2 and MOD11A2 was used in this study with the approximate of coverage area around $1 \mathrm{~km}^{2}$ and recording interval of 8-day. Both products can provide LST (land surface temperature), they give two LST retrievals per day around 12-14 and 1-3 that relatively close to the maximum and the minimum time of air temperature value in the diurnal cycle. Concurrent air temperature data was measured using Automatic Weather Station (AWS) from Japan Meteorology Agency (JMA), with coordinate location (longitude: 136 45.7' E, latitude: $35^{\circ} 24.0^{\prime} \mathrm{N}$, altitude: $12.7 \mathrm{~m}$ above sea level). Observation period spans from January 2014 to March 2017.

How to get MODIS data

Open: https://daac.ornl.gov/MODIS/ by your computer, choose "Create Subset" (see right bottom). 
Specify the coordinates for the center of the area of interest: Insert the coordinate data (longitude and latitude) can use direct GPS data or estimating using Google Earth. Click "continue".

Select product and sub size then continue: select MOD11A2 or MYD11A2 and replace "3" to "0" in the bottom table. Click "continue".

Select a date and provide email then place an order: select starting date and ending date and fill your email address in the bottom. Click "Review Order".

Order summary: Click "create subset"

After around 1 hour, some information comes to the email.

Click on the following URL to obtain your result

Data visualization and download: choose "download data"

Download data: "statistics_LST_DAY_1 km.asc" and "statistics_LST_Night_1km.asc".

Copy and paste to excel or notepad and manually extract.

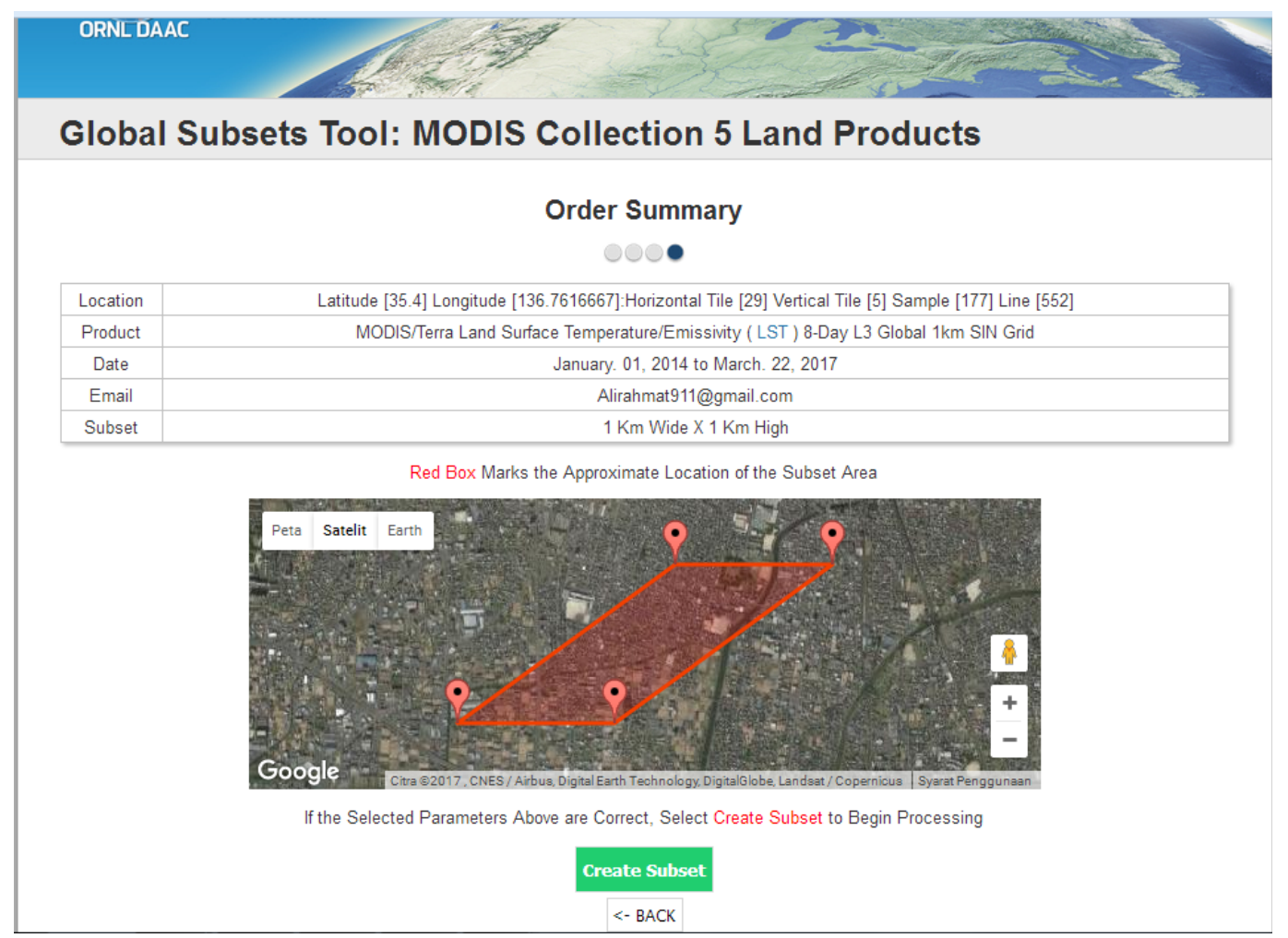

Figure 1. Observation area

\section{RESULTS AND DISCUSSIONS:}

Air temperature is an important component of climate condition and it can be used to predict environmental condition in some area [5]. This study aims to estimate air temperature using satellite data (MODIS). According to the Figure 2, air temperature data can only be captured by the satellite one time in the afternoon and in midnight that represents the maximum air temperature and minimum air temperature respectively. Meanwhile, the average of air temperature can be determined by calculating the mean of minimum and maximum air temperature. It is also can be known from the Figure 2 that the maximum air temperature measured by the satellite data is higher than those measured by direct measurement from the local meteorological station. However, the minimum air temperature data is relatively closed with the data obtained from meteorological station. Furthermore, the average temperature data obtained from the satellite is higher than ground observation data yet the value is closer to the local meteorological station (ground measurements) compared with the maximum or minimum air temperature data.

According to the research conducted by [6], Some equations from linear regression can be produced as long as there are ground measurement data. Nonetheless, in remote areas such as desert or forest, that type of data is relatively difficult to be obtained. Therefore, it is impossible to produce the equations of linear regression. However, according to the Figure 3, 4, and 5, some equation can be produced by substituting the ground measurement data with the data extracted from satellite imagery. 
The $\mathrm{R}^{2}$ of all equations are more than 0.8 which means the relationship of the data is strong. It can be observed that the ground measurement data can be approached and substituted by satellite data. It is observed that the product of MOD11A2 always has higher $\mathrm{R}^{2}$ than the MYD11A2 product in which the data produced by MOD11A2 is closer to the observation data from the local meteorological station than the MYD11A2 product.

Nonetheless, satellite data extracted from MODIS LST have some drawbacks. It has a relatively low spatial resolution that measured the temperature data of $1 \mathrm{~km}^{2}$. In fact, the MODIS LST data is better in predicting air temperature in scale more than $1 \mathrm{~km}^{2}$. Moreover, MODIS LST collects the data in particular area every 8 days, starting on 1 January every year. MODIS LST data cannot produce the air temperature data in hourly basis. It is not exactly known the exact time of the satellite capturing the image of the land surface. The intactness of the data collected is also strongly influenced by cloud condition in the atmosphere. Moreover, the data processing is also quite complicated. In order to obtain the air temperature data, the satellite image from the website must be extracted manually 0 excel or notepad and the file only can only be accessed in 30 days after ordering the data.

\section{CONCLUSIONS:}

Data from MODIS LST is higher than data directly measured from the local meteorological station for day time while the data extracted from MODIS LST is lower at night time compared with direct measurement. However, it still can be used because the pattern is relatively similar. Moreover, the average of maximum air temperature and minimum air temperature can represent the daily average of air temperature. It is also certain that MOD11A2 product data is better than MYD11A2 data in estimating air temperature. Even though the MODIS LST has several limitations, the data still can be used to predict air temperature especially for remote areas like desert or forest where the ground measurement station has not been established. 

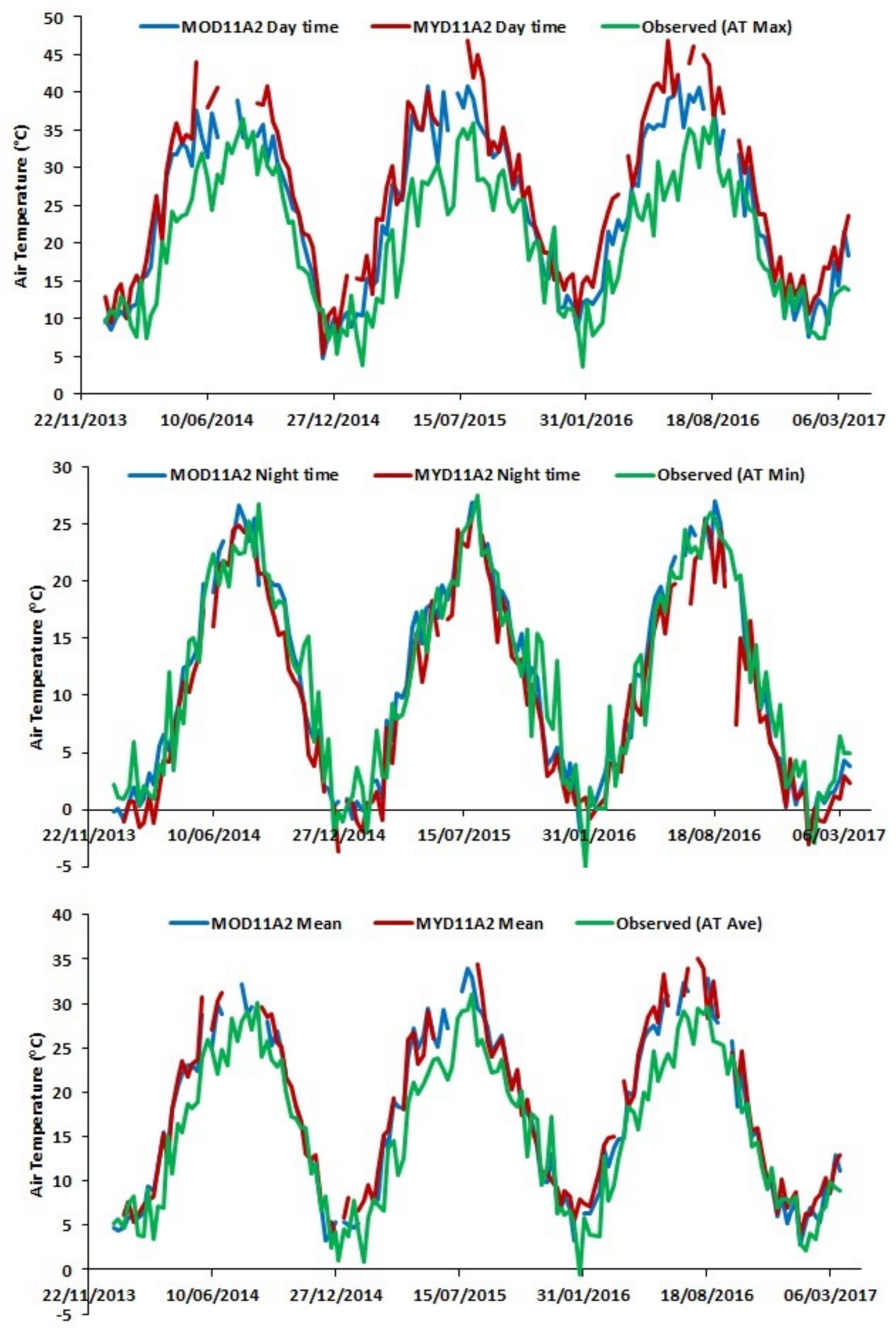

Figure 2. Time series of satellite and ground observation data (up max, middle: min, bottom: ave) 

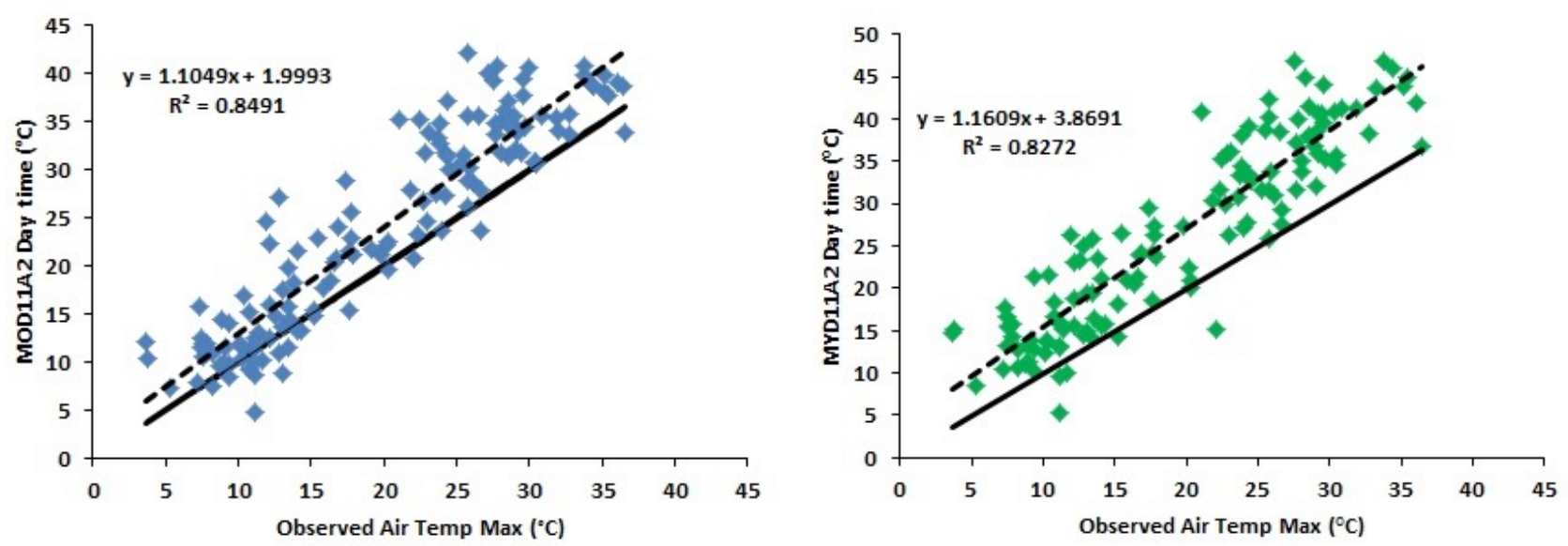

Figure 3. Linear regression maximum air temperature of satellite and ground observation data (left: MOD11A2 product, right: MYD11A2 product)
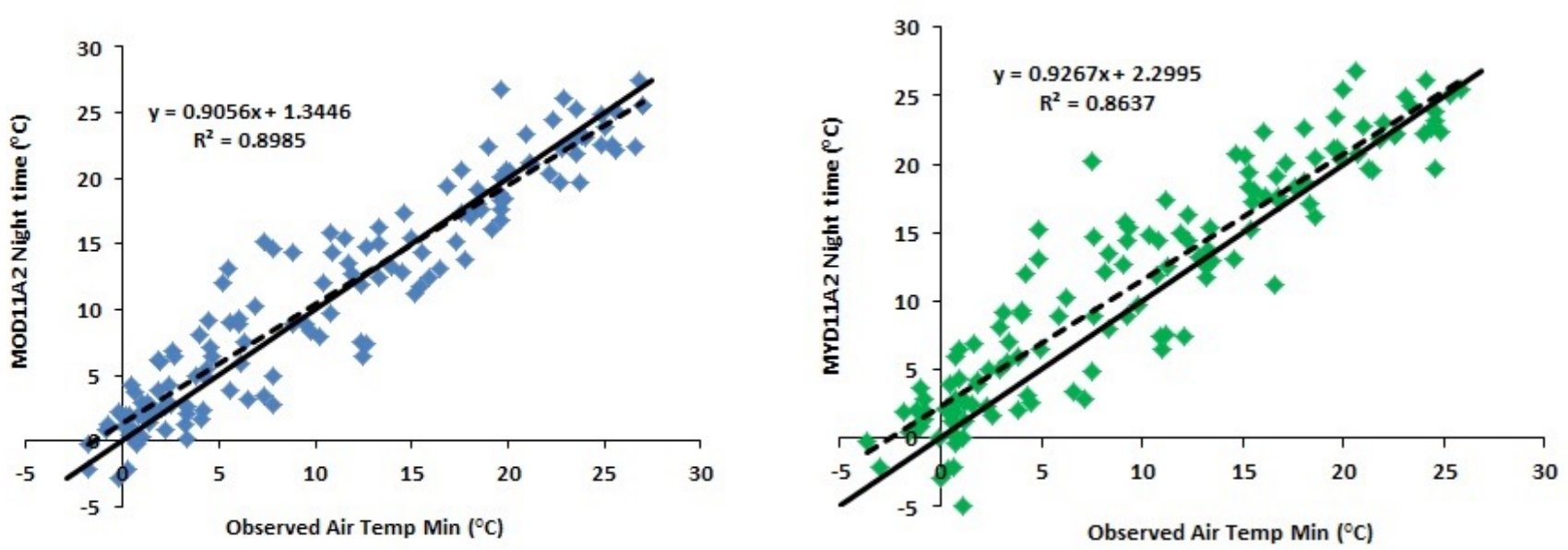

Figure 4. Linear regression minimum air temperature of satellite and ground observation data (left: MOD11A2 product, right: MYD11A2 product)
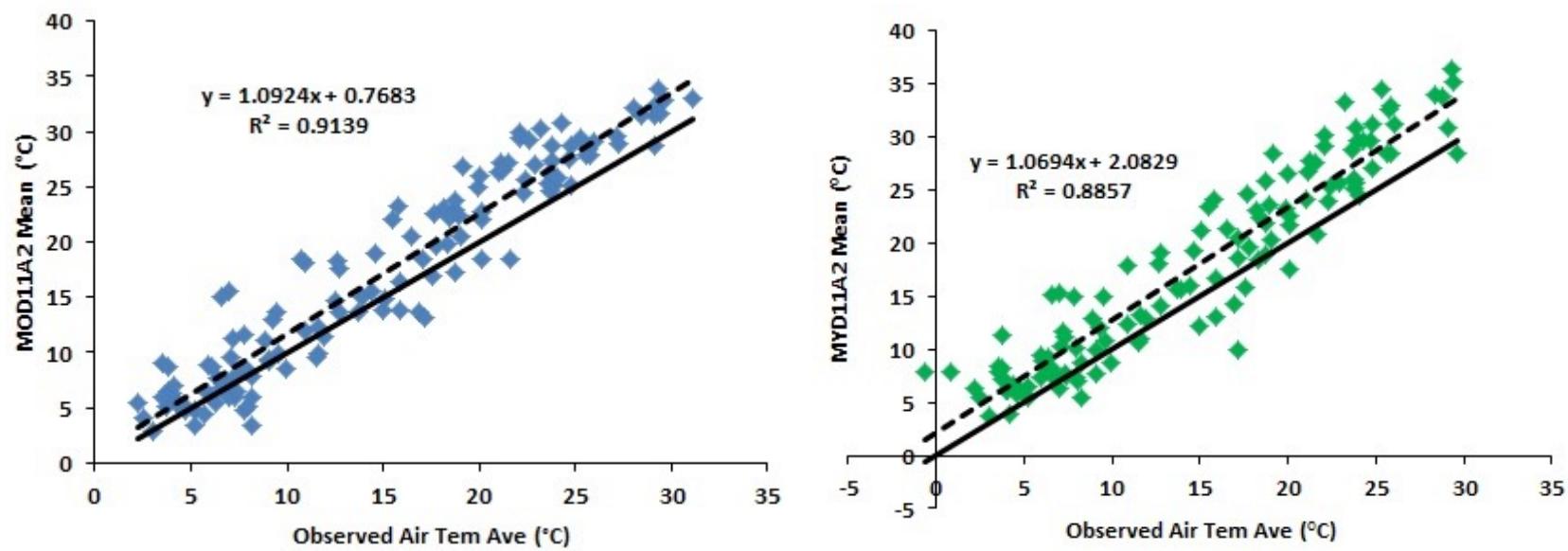

Figure 5. Linear regression average air temperature of satellite and ground observation data (left: MOD11A2 product, right: MYD11A2product) 


\section{REFERENCES}

[1] Benali, A., Carvalho, A. C., Nunes, J. P., Carvalhais, N., and Santos, A.: Estimating air surface temperature in Portugal using MODIS LST data, Remote Sens. Environ., 124, 108-121, doi:10.1016/ j.rse.2012.04.024, 2012.

[2] De Bruin, H.A.R.; Trigo, I.F.; Jitan, M.A.; TemesgenEnku, N.; van der Tol, C.; Gieske, A.S.M. Reference crop evapotranspiration derived from geo-stationary satellite imagery: A case study for the Fogera flood plain, NW-Ethiopia and the Jordan Valley, Jordan. Hydrol. Earth Syst. Sci., 14, 22192228. 2010.

[3] Lin, S. P., Moore, N. J., Messina, J. P., DeVisser, M. H., and Wu, J. P. "Evaluation of estimating daily maximum and minimum air temperature with MODIS data in east Africa". Int. J. Appl. Earth Obs. vol 18, 128-140, doi:10.1016/j.jag.2012.01.004, 2012

[4] Lofgren, B.M.; Hunter, T.S.; Wilbarger, J. Effects of using air temperature as a proxy for evapotranspiration in climate change scenarios of Great Lakes basin hydrology. J. Gt. Lakes Res. 37, 744-752. 2011

[5] Rahmat, A., \& Mutolib, A. Comparison air temperature under global climate change issue in Gifu city and Ogaki city, Japan. Indonesian Journal of Science and Technology, 1(1), 37-46. 2016.

[6] Colombi, A., Michele., CD, Pepe, M.,and Rampini,A. Estimation of daily mean air temperature from MODIS LST in Alpine areas. EARSeL eproceeding 6. pp. 38-46. 2007 